\title{
The Behavioral and Evolutionary Roots of Dynamic
}

\section{Capabilities}

November 10, 2016 


\begin{abstract}
Although the dynamic capabilities framework has proved important for explaining longterm competitive advantage, some scholars have attacked it as lacking theoretical underpinnings. In this paper, we clarify the lineage of the "dynamics" in the dynamic capabilities framework from the non-strategic model of Cyert and March to the dynamic evolutionary theory of the firm in Nelson and Winter that enabled the initial breakthrough of Teece, Pisano and Shuen. We explain that the theoretical schism in dynamic capabilities between the tradition of Eisenhardt and Martin and that of Teece and colleagues can be traced to their relative emphasis on behavioral versus evolutionary theories. Finally, we provide a brief overview of implications for emergent topics and empirical research, along with ideas for future research.
\end{abstract}




\section{Introduction}

One of the key contributions of dynamic capabilities theory (Teece, Pisano, and Shuen, 1997) to the field of strategy is to highlight that firm performance over time critically depends on the ability to align and realign resources to the ever-changing challenges and opportunities of complex and uncertain business environments. The epistemological roots of dynamic capabilities lie in part in the organizational routines that Nelson and Winter (1982) conceptualized as the firm's repositories of regular patterned behaviors and the firm's stored knowledge. Nelson and Winter provided crucial insights for firm strategy by translating the relatively static standard operating procedures from Cyert and March (1963) into a dynamic environment informed by Schumpeterian ideas of innovation. The development of these key insights has resulted in the valuable literature on dynamic capabilities, yet the critical contributions of Cyert and March (1963) and Nelson and Winter (1982) toward this research stream remains underappreciated. We argue that the intellectual foundations in the behavioral and evolutionary theories of the firm can help to clarify the theoretical primitives of dynamic capabilities and in turn address important unanswered questions in the literature.

Our aims with this paper are threefold. First, we address concerns about the theoretical foundations of dynamic capabilities (for a review see Barreto, 2010). In their empirical assessment, DiStefano, Peteraf, and Verona (2014: p.309) argued that dynamic capabilities are strongly related to evolutionary economics, but commented that 'the extent of the influence of evolutionary economics on the development of dynamic capabilities is not so 
apparent.' As a response, we detail the critical step of Nelson and Winter in translating the behavioral theory into the dynamic capability theory of the firm.

Second, we explain how these foundations in Nelson and Winter can help resolve theoretical confusion around dynamic capabilities that has emerged from a second view with sharp contrasts to the Teece, Pisano, and Shuen conceptualization (Arend and Bromiley, 2009; Schreyögg and Kliesch-Eberl, 2007; DiStefano et al., 2010; Peteraf et al. 2013). This view, introduced by Eisenhardt and Martin (2000: p. 1105), argues that dynamic capabilities often take the shape of "best practices" or - in fast changing environments - “simple rules". Emergent from Eisenhardt's earlier work on firm-level heuristics (Eisenhardt, 1998; Brown and Eisenhardt, 1997; 1998), and emphasizing elements of the behavioral theory of the firm, they argue that dynamic capabilities as best practices are unlikely to lead to sustainable advantage, but are instead a source of temporary competitive advantage. Our paper explains why and how Eisenhardt and Martin's (2000) framework is a special case of Teece and colleagues' theory that emphasizes behavioral theory elements in lieu of the evolutionary theory emphasis in the work of Teece.

Finally, we identify the firm's management as drivers of dynamic capabilities by their shaping of rules, decision-making procedures, and capabilities. We outline areas that have not attracted sufficient attention, partly because of the enduring tension between the behavioral and evolutionary foundations reflected in the Eisenhardt and Teece schools today. 


\section{The Two Schools of Dynamic Capabilities}

We first depict differences between the more rigid conceptualization of dynamic capabilities in the work of Eisenhardt and colleagues and the more evolutionary view of Teece and colleagues. Although these differences have been explicitly covered in previous work (Peteraf et al. 2013), their relative influences by the behavioral and evolutionary theories has not yet been explored.

The dynamic capabilities view introduced by Eisenhardt and Martin (2000) is inherently a subset of the framework argued by Teece et al. (1997) and subsequent papers. As Winter (2003) and others (Peteraf et al., 2013) note, the low-level routines in Eisenhardt and Martin (2000) form only a subset of the capabilities available to firms - those that are easier to observe and to empirically investigate. Indeed, Teece (2007) is explicit that best practices aren't necessarily dynamic capabilities. The capabilities in Eisenhardt and Martin, are most similar to the standard operating procedures that define firms in the behavioral theory. Teece (2014a, 2014b) calls these ordinary capabilities, and argues that they are quite distinct from dynamic capabilities.

A firm for Teece and colleagues is capable of shifting its capability portfolio in times of change through innovation. For modeling these ideas, they use a combination of Schumpeterian innovation, higher-order routines, and a progressive application of problemistic search. The focus is on strategic elements that enable firms to be constantly one step ahead of their competitors. At the core of this concept is the idea of heterogeneous 
firms that are limited by their cognitive biases and entrepreneurial capacity for shifting resources and capabilities, while trying to challenge the status quo.

In contrast, Eisenhardt and Martin (2000) equip firms in the same industry with a reasonable amount of competitive homogeneity expressed through significant commonalities across capabilities that they call 'best practices'. Many of the underlying assumptions are focused on imitation rather than innovation and operational concerns rather than strategic differentiation. The explicit purpose is empirical identification (Eisenhardt and Martin, 2000: p. 1106) rather than formal rigor. As a consequence, the idea of industry evolution remains underdeveloped. Rather than a strategic response to environmental change, Eisenhardt and Martin (2000) suggest that dynamic capabilities take on the shape of best practices and simple rules as decision making heuristics. They render strategic differentiation beyond a cost benefit approach of adapting best practices at best unlikely.

The critical higher order routines that involve identifying and targeting "new forms of competitive advantage" (Teece et al., 1997, p. 515) are direct descendants of the evolutionary theory. They are the reason why simple rules (which are easily observable) are perceived as 'unstable and ephemeral, the system as a whole is not' (DiStefano et al., 2014: p. 321). As Winter (2003) emphasizes, such higher-order dynamic capabilities are costly to develop and maintain, and thus cannot be ubiquitous. This implies that they indeed present the potential for sustainable competitive advantage, a condition supported by recent 
empirical work. Using a large-scale longitudinal sample, Klarner and Raisch (2013) show evidence that firms that are capable of continuous change consistently outperform rivals.

The differential emphasis between the two schools on the behavioral versus evolutionary elements is especially visible in that Eisenhardt and Martin (2000) believe that the evolution of markets in rapidly changing environments become so chaotic as to render firms incapable of foreseeing or steering these developments. In this view, although industry dynamics are important, existing firms are incapable of creating or exploiting the creative destruction in the way that new firms can. In contrast, Teece and others (Adner and Helfat, 2003; Augier and Teece, 2009; Helfat and Peteraf, 2015) emphasize the entrepreneurial capability within a firm of top management team and others to adapt to and influence these rapidly evolving environments. In many ways, this division represents the duality in Schumpeter's view of innovation and industry evolution. On the one hand, he champions the process of creative destruction brought on by processes and actors exogenous to the firm. On the other hand, he explains the capability of large incumbents to achieve sustainable competitive advantage through reinvestment. The schism between the two dynamic capabilities approaches represents the boundary conditions that might delineate when it is no longer feasible for an incumbent firm to achieve the dynamic capabilities to shape and exploit industry evolution.

Following Peteraf et al.'s (2013) aspiration for a unification of the frameworks, we believe that this duality, both in Schumpeter and Nelson and Winter, can help clarify the theoretical underpinnings of the two conceptualizations. Most importantly, it can clarify where these 
boundary conditions exist, and whether the rapid-change environments argued by Eisenhardt and Martin (2000) to destroy sustainable advantage are widespread, or instead represent only the few extreme cases where higher order dynamic capabilities are infeasible. This study could be a first step into this direction.

DiStefano et al. (2014) identify several elements that they consider to be the core differences between the two seminal papers on dynamic capabilities by Teece et al. (1997) and Eisenhart and Martin (2000). Our paper adds to their work by showing in more detail how the behavioral and evolutionary roots have affected the two conceptualizations of dynamic capabilities and explains the implications that the different use of behavioral and evolutionary constructs had for each of the dynamic capability constructs. In the following paragraphs, we discuss these elements and the duality between the importance of observability of dynamic capabilities emphasized by Eisenhart and Martin (2000) and the more holistic view that Teece et al. (1997) tried to advance.

\section{The Behavioral Theory of the Firm and Strategy}

The behavioral theory of the firm provided many of the important foundations for both the Teece and Eisenhardt views of dynamic capabilities. Cyert and March built a theory of organizational behavior that facilitated the development of strategic theories in which organizational heterogeneity plays a crucial role. Four elements of the behavioral theory of the firm anchor Cyert and March's framework: organizational goals, expectations, choice, and control. Organizational goals describe the process through which individuals and coalitions of individuals process information and participate in the goal setting process of 
the organization. Different groups follow their own agenda and goal conflict is frequent. Resource allocation becomes an issue when resources are scarce and only partially or not available to some groups for fulfilling their interests. Such conflicts are potentially harmful to the organization. In dynamic capabilities theory, the solution to these conflicts are represented in the conceptualization of decision-making that maps dominant coalitions into entrepreneurial actors and teams.

The concept of bounded rationality, previously discussed in March and Simon (1958), played a critical role in the conceptualization of organizational expectations in Cyert and March by suggesting limited information processing capacity in management. Simon's $(1955,1957)$ idea of satisficing expectations rather than finding global maxima was another influential idea for Cyert and March because the limited information processing capacity of managers gives them an incomplete picture of the situation, diminishes the available options for courses of actions, and renders them incapable of understanding optimality.

These behavioral elements have shaped dynamic capabilities through the concept of sensing, which implies heterogeneity in foresight, biases and other cognitive processes. Bounded rationality makes sensing both incomplete and heterogeneous, creating the potential for some firms to be better at it than others. This idea evolved from the concept of search that exists in different versions in both the behavioral and the evolutionary theory. For example, while the concept of best-practice might be informed through local search, the idea of higher-order routines draws on the concept of problemistic search. The firm searches for working (satisfying) configurations which is harmed by boundedly rational 
and biased actors. Scholars have begun to study the cognitive and affective microfoundations of dynamic capabilities theory that will further illuminate the importance of the behavioral theory's bounded rationality assumptions in long-term competitive advantage (Hodgkinson and Healey, 2011).

Cyert and March's conceptualization of choice may provide their largest contribution to dynamic capabilities theory. Choice maps into Teece's (2007) concept of "seizing," introducing standard operating procedures as decision rules that help govern how firms react to environmental cues and opportunities. Standard operating procedures are unique to each firm, and the firm is presented as adaptively rational. The logic of standard operating procedures is such that they produce consistency throughout the organization, helping task coordination between units and resulting in retention processes within the firm to ensure stable outcomes. As such, standard operating procedures represent the way information is absorbed, transmitted and stored within the firm.

Cyert and March present standard operating procedures as the way in which a firm exercises control. The four major types of specific standard operating procedures are task performance rules, continuing records and reports, information handling rules, and plans. Task performance rules deal with the specification of methods for accomplishing a variety of tasks, including pricing, production procedure, and accounting procedures. Continuing records and reports concern the documentation and codification of all elements of business operations important to the firm. Plan procedures define the firm's intent and ability to innovate and evolve, its dynamic capabilities in particular directions. This 
conceptualization has many advantages and may describe ordinary capabilities as well as 'best practices'. As such, it partly maps into the third pillar of dynamic capabilities of 'transformation' - sometimes labeled 'alignment'. However, the behavioral foundations and the concept of 'best practices' do little to explain how firms can ensure that the standard operating procedures of today do not represent the best practices of yesterday in the face of innovation and change.

The four elements of the behavioral theory of the firm play an important role for today's interpretations of dynamic capabilities. Eisenhardt and Martin (2000) emphasized the concept of 'best practices' that strongly resemble the relative static standard operating procedures, local search, and decision-making through the dominant coalitions of Cyert and March (1963). In this sense, Eisenhardt and Martin (2000) built their interpretation of dynamic capabilities around the cornerstones of the behavioral theory.

Many of the elements of the behavioral theory of the firm inform the way Teece et al. (1997) interpret dynamic capabilities. Organizational expectations are described as the process with which the organization collects and interprets information from its environment—what Teece (2007) calls “sensing." Cyert and March's conceptualization of choice maps into Teece's (2007) concept of "seizing," introducing standard operating rules that help govern how firms react to environmental cues and opportunities. Cognitive dimensions also matter in the Teecian Framework. Teece's (2007) idea of 'transformation' is informed by the way in which Cyert and March (1963) describe control. Standard operating procedures specify how tasks should be accomplished, documented, and 
processed. In both interpretations, the behavioral theory was an important precursor to the development of dynamic capabilities.

\section{Routines as the Evolutionary Theory in Dynamic Capabilities}

Although the behavioral theory provided the foundation for both the Teece and Eisenhardt views of dynamic capabilities, Nelson and Winter's evolutionary theory was uniquely important for the Teecian conceptualization of dynamic capabilities that enabled firms to successfully adapt to even highly turbulent environments. The standard operating procedures in the behavioral theory fundamentally represent a rigid and necessarily path dependent firm. As in Eisenhardt and Martin (2000), such a firm is powerless to sense and seize opportunities in rapidly evolving markets. Nelson and Winter, however, introduced the concept of routines to address their key interest in 'the dynamic process by which firm behavior patterns and market outcomes are jointly determined over time' (1982, p. 18). Their conceptual firms possessed the potential for change through routines that were more than just standard operating procedures - they were decision rules and patterns of behavior that defined not just current behavior but also intentional adaptation.

While the static routines in Nelson and Winter resembled standard operating procedures, dynamic routines became the foundation for the dynamic capabilities theory introduced by Teece and colleagues. Static routines allow the firm to replicate certain previously performed tasks, and although they are generally stable, improvements and mutations will always occur repetitively. Like standard operating procedures, these most closely resemble the operations of firms in the Eisenhardt view. Firms can change, but only so much, and 
they are powerless to strategically address major shifts in markets or technology. Dynamic routines are those that seek new product, process, and business model innovations. They are heavily influenced by the research and development a firm pursues, along with the firm's extended technology acquisition activities. R\&D investments and the distinct technologies that emerge render replication or imitation difficult, yielding the possessors of such routines sustainable competitive advantage through dynamic capabilities.

The concept of dynamic routines was inspired by the ideas of Schumpeter (1934), who emphasized that markets do not only strive toward equilibrium, but are frequently (proactively) creatively destroyed into disequilibrium. In Schumpeter's world as well as in the behavioral theory of the firm, it was unclear how firms could use routines or standard operating procedures to produce innovations to address such creative destruction. They lacked intentionality and strategic persistence, and like firms in the Eisenhardt view, were mostly powerless to adapt to major environmental change. Nelson and Winter expanded standard operating procedures into routines that could create novelty through intentional combination, recombination, and (imperfect) imitation of routines, and also through the somewhat random and unforeseeable mutation of routines (Becker, Knudsen, and March, 2006). This potential for dynamic change provided the foundation for the asset orchestration and entrepreneurship in the Teece view.

By creating dynamic routines, Nelson and Winter enable firms to understand market structures and their positions within markets, to develop co-evolutionary responses to existing and evolving market structures and thereby foresee and produce market changes. These insights enabled Teece et al. (1997) to build their idea of dynamic capabilities with the three Ps (position, path, processes). Nelson and Winter equipped firms not only with 
the ability to adapt to external environmental changes (exogenous innovation), but also to proactively shape their environments (endogenous innovations). This conceptualization of dynamic routines as (at least partly) intentional and strategically persistent was critical for the development of the dynamic capabilities theory because it provides firms with insights about markets. Remarkably, the combination of evolutionary theory and Schumpeterian innovation has attracted much attention (Cohen, 2006; Levinthal, 2006; Winter, 2006), but has - despite its central role for understanding the mechanisms of dynamic capabilities not been made sufficiently visible in the theory of dynamic capabilities.

Another way that Nelson and Winter integrate dynamic elements into their evolutionary theory is the idea of three different classes of routines. Firms evaluate potential routine alterations by the criterion of anticipated profit. These three classes of routines reflect the existence of a tradeoff between 'static efficiency' and 'technological progressiveness' (Nelson and Winter, 1982b: p. 115). The first of these classes includes the short-run procedures that determine how the firm uses its current capital stock. The second group of routines determines how the firm alters its capital stock across periods in response to environmental stimulus. The third set of routines are those which over time alter certain aspects of operating characteristics. They define how the firm critically analyzes the existing operating routines and decides whether or not to alter them. Nelson and Winter argue that top-level routines, which serve to alter other routines, define the probability distribution of what routine modifications or new routines will be found through search. These insights, informed by the integration of Schumpeterian innovation, have been expanded in the Teecian dynamic capability view through the concept of evolutionary 
fitness, and the mechanisms of capability reconfiguration through capability evolution, transformation and substitution (Lavie, 2006).

Nelson and Winter (1982: p. 36) make two important contributions that enable them to create 'an explicit theory of industry behavior' based on a 'much simpler and more stylized' characterization of individual firms. First, they provide a clear idea of the objective of decision-makers and thereby unify the multiplicity of objectives modeled in Cyert and March's behavioral theory. Second, they identify routines as a dynamic source of uniqueness. Both contributions are further developed and advocated for in the theory of dynamic capabilities, but it is the second that distinguishes Teece from Eisenhardt. Not only is a firm capable of unifying objectives, but the entrepreneurial management of the leadership team guides the firm and can create, shape, and transform markets (Teece, 2007, 2014a, 2014b).

\section{Specific Theoretical Differences and Their Origins}

In this section, we address specific differences in the Eisenhardt and Teece views. Our list is far from exhaustive. Rather, it represents a starting point for a discussion of the differences between the two views on dynamic capabilities and their implications. We aggregate some of the elements to deliver a more comprehensive discussion.

\section{Environmental change and flexibility}

The role and value of dynamic capabilities for flexibility in different environments has attracted rich discussion. We argue that some of the disagreement in this matter can be 
traced back to the differences between the Eisenhardt and Teece views based in behavioral and evolutionary roots.

Teece presents dynamic capabilities as co-evolutionary and reactive forces to environmental changes - a view informed by Schumpeterian and Kirznerian concepts of opportunities. Disequilibrium enables firms to continuously identify and seize opportunities. Timing matters. Combining the elements of search, choice, and control, Teece (2007) maps out the dimensions of dynamic capabilities sensing, seizing and transforming. The emphasis of dynamic capabilities in the tradition of the 3Ps (position, processes, paths) with deep roots in evolutionary thinking from higher-order routines, pathdependence, and learning is on strategic differentiation and changes of capability portfolios over time. The conceptualization builds on an evolutionary, strategic view of the firm.

In contrast, Eisenhardt and Martin (2000) focus on processes such as 'how' strategic decisions are made and 'best practices' that explain how the firms adopt its core activities to industry standards. Their best practices are descendants of standard operating procedures. The Eisenhardtian firm tends to be driven by its environment. It exists in a competitive landscape that is focused by imitation and replication. Competition is described through the acquisition of best practices that at best lead to temporary competitive advantage. In fast changing environments, decision speed and simplicity for adopting new experiential simple rules render a firm dynamically capable (Baum and Wally, 2003). The emphasis is on behavioral elements such as decision-making processes and overcoming conflicts (for example through simple rules). 


\section{Search and bounded rationality}

Teece's three dimensions of dynamic capabilities imply a progressive development of the traditional concept of problemistic search. Sensing opportunities include the continuous attempt of an organization to search for a problem definition that either results from a performance aspiration gap or the identification of an opportunity to better perform or utilize an existing bundle of resources in an alltogether more advantageous way. The second step of problemistic search is then called 'seizing' - traditionally conceptualized as solution search and selection (choice). The first two stages are associated with intensive cognitive efforts that traditionally have been lumped together under the umbrella of bounded rationality. Possibly one of the most important contribution of Teece's dynamic capabilities is the way he describes bounded rationality and simple mindedness of behavioral and evolutionary actors; a field that has drawn attention as the cognitive microfoundations of dynamic capabilities. Finally, Teece's view on dynamic capabilities suggests that 'transformation' is the ability of a firm to reallocate and reorchestrate a firm's resource in a manner that implements the envisioned solution. This dimension of dynamic capabilities can be traced back to a combination of the behavioral concept of control and particularly the element of planning with the evolutionary concepts of dynamic and higherorder routines.

In contrast, the Eisenhardtian idea of dynamic capabilities has more resemblance to the concept of local search. She conceptualizes search activities as ending in best practices local maxima - and describes them in highly volatile environments as heuristics manifested 
in simple rules. These ideas resemble the simple-mindedness of actors and their limited rationality described in the concept of search within the behavioral theory of the firm.

\section{Fitness}

Teece draws on the idea of evolutionary fitness that balances explorative and exploitative activities of the firm for future survival (March, 1991). Both concepts resemble elements from the behavioral and evolutionary schools. Exploitation draws on static routines that become stronger with repetition and are idiosyncratic to the firm. Exploration relates to those innovative efforts that Nelson and Winter included in their evolutionary theory of the firm to equip it for long-term survival such as a certain degree of mindfulness through intentionality and strategic persistence.

In Eisenhardt and Martin (2000) the aspect of long-term survival is less clear. Changing environments lead actors to simplify their routines in unstable, experiential processes. Just like those actors in the behavioral theory that face difficulties agreeing on a mutual vision for the firm, survival skills depend on fast, unstable, and experiential adaptation processes.

\section{Character of routines and evolutionary emphasis}

Both author groups take a different stance on the role of routines. Teece and colleagues interpret them in an evolutionary tradition that emphasizes the role of higher-order routines and mindful planning. Dynamic capabilities are described as highly strategic, multi-level concepts that are heterogenous across firms and thus potentially capable of generating sustainable competitive advantage. For Eisenhardt and Martin (2000), routines resemble 
standard operating procedures with their different classes that feature commonalities across firms and are only idiosyncratic in their details. These equifinal routines offer a short-lived competitive advantage through early adoption until they are copied by competitors (Arndt and Bach, 2015).

While this list and the detailed description of how the two concepts draw on behavioral and evolutionary elements is incomplete, we believe that they start a necessary detailed discussion about the different roots of the two concepts of dynamic capabilities that both have attracted much scholarly attention in the last two decades. For example, we detect fundamental differences in the understanding of routines tied to standard operating procedures that were designed to help modeling firm behavior and routines that are based on evolutionary thinking that was designed to model industry evolution. These contrasting aims of the two theories have led to two fundamentally different conceptualization of dynamic capabilities that have been underplayed through linguistic similarities, but become apparent when looking at the underlying understanding of the concept of bounded rationality, search, routines, evolutionary fitness/survival, and resource heterogeneity.

\section{Dynamic Capabilities: Directions for Future Research}

If indeed the key difference between the Teece and Eisenhardt schools of dynamic capabilities is their relative emphasis on evolutionary versus behavioral elements in the ability of the firm to strategically adapt to a dynamic environment, it is crucial for present and future theoretical contributions to detail exactly how such strategic adaptation occurs. While we have argued for a divide between the dynamic capabilities of Teece and 
Eisenhardt and Martin that warrants clear distinction, we view Eisenhardt and Martin's dynamic capabilities as a special case of dynamic capabilities. If so, rather than focusing on the divide, we suggest to be more explicit about those behavioral, evolutionary and dynamic capability elements that are new and may benefit from more attention.

Cyert and March recognized the importance of standard operating procedures for the workings of the firm just as Nelson and Winter recognized the importance of routines that alter the capital stock. Both author groups understandably did not detail the key issues and mechanisms of resource allocation given their focus on organizational behavior and industry evolution. These mechanisms are crucial for a theory of the firm that explains sustainable competitive advantage (Zott, 2003). For Teece, they are the heart of dynamic capabilities. He emphasizes several factors that are not necessarily defined by routines, but are also not ad hoc (Winter, 2003). Instead, these factors make up the entrepreneurial part of dynamic capabilities. These factors are (1) selection of business models, (2) investment decision criteria and choices, (3) the development and acquisition of complementary and cospecialized assets, and (4) asset orchestration activities of management. They depend in part on the entrepreneurial capacities of management, and the governance/leadership structure of the firm - a primary contribution of the theory of dynamic capabilities with the goal of explaining competitive advantage. We briefly elaborate on these factors below and discuss how they a) stimulate new research directions and b) indicate their theoretical roots in behavioral and evolutionary elements. 
Discovering and honing the right business model and the right strategy are key success factors for firms operating in uncertain fast changing business environments. Teece (1986), Chesbrough and Rosenbloom (2002) and Teece (2010, 2014a, 2014b) stress the critical role of business models and strategy. Getting the strategy and the business model right matters. Sony lost with its arguably superior Betamax technology standard over Matsushita's VHS standard because Matsushita adopted a more collaborative strategy, recognizing early on the 2-sided market (Evans, 2003) issue that it was confronting. Also, Dell's success in the PC business and Wal-Mart's success in retailing are based on their ability to design and implement superior organizational arrangements for going to market. These examples illustrate that dynamic capabilities are more than just routines (Schreyögg and Kliesch-Eberl, 2007). We doubt that developing a business model can be routinized. Yet neither can it be merely ad hoc.

The business model sets the architecture of a business; developing a new model involves creative acts --- in the case of Dell and Wal-Mart, it involved the use of new information technology to revolutionize the supply chain. The necessary skills and insights often come from entrepreneurs, actors largely missing from Cyert and March. Even Nelson and Winter, who view change routines as adaptive mechanisms, do not capture the entrepreneurial acts that transcend adaptive capacities, and are ultimately proactive (Staber and Sydow, 2002). As Schumpeter noted, these activities involve "new combinations" which are not simply adaptive. A brilliant entrepreneur can string together a series of insights and see clearly possibilities that have always existed but have simply not been recognized by others. While the focus in studying entrepreneurial activity has been in high 
technology industries, these combinations, in our view, can, but need not be, new technologies (Markides, 2006).

The astuteness with which investment choices are made inside the enterprise is also of critical importance. While small (incremental) investments made as part of the firm's annual capital budgetary cycle can be routinized, we believe there is an important class of large irreversible investments which cannot be routinized and involve judgment calls by management and the board of directors. Included in this category are large mergers and acquisitions. While elements of these decisions (e.g. legal due diligence, valuation) may be routinized, issues around strategic fit involve critical elements of managerial judgment. Good governance from tough-minded boards of directors can undoubtedly help steer management away from egregious errors. Quality judgments about the likely evolution of technologies and markets are critical to success. While models exist for valuing assets under uncertainty, ${ }^{1}$ there remain important visions to be articulated, and judgment calls to be made. The genius (or lack thereof) and judgment of the top management team has to be important to this process (Klarner and Raisch, 2013; Laureiro-Martinez et al., 2015).

Another missing element to build a theory of firm-level competitive advantage is the recognition of the distinctive asset orchestration roles that management can play. An important source of competitive advantage that firms possess is the unique value creation opportunities that can flow from employing specific assets/resources inside the firm (Augier and Teece, 2009). These assets can sometimes be secured externally (possibly

\footnotetext{
${ }^{1}$ Monte Carlo simulation models can assist in this process.
} 
through M\&A activity) or built internally (Vandaje and Zaheer, 2014). Because there is not a well-developed market for idiosyncratic assets, they can sometimes be secured on advantageous terms. Once under managerial control, they can be orchestrated to yield products and services that are differentiated. Such differentiation based on difficult to imitate resources/asset combinations can be a source of rent, if demand conditions are satisfactory. The ability of (entrepreneurial) management to co-align idiosyncratic assets in a semi-continuous fashion is an important dynamic capability (Durand, 2003).

The research area of capability hierarchies and capability development seems promising in connecting capability theory across levels (Kaplan, 2011; Schreyögg and Sydow, 2010). Laamanen and Wallin (2009) clarify the role of distinct levels within the firm for capability portfolio development. They suggest that the alteration of different levels of aggregation is based on differences in cognitive processes and mental maps of decision makers (Gary and Wood, 2011). Whereas for operational capabilities local search is important, on a firm level, awareness of different evolutionary paths becomes the primary selection antecedent (Ocasio, 1997). From the enterprise stance, differences in foresight are a major driver of heterogeneous capability development among firms. Consistent with these findings, Gavetti (2005) suggests that cognition in organizations is located on different levels. These studies suggest that agents on different levels may play a role and that we need to know more about the interactions between different levels to disentangle dynamic capabilities. Advancing dynamic capability theory then means to better understand the interaction across organizational levels not only between managers, but also between resources available on different levels, and effect of leadership structure across levels. Overall, we 
need to better capture the interactions within the triangle of microfoundations including cognition, hierarchy and the role of the management.

Research on dynamic capabilities has also highlighted the central role of learning (Winter, 2003). Many of the elements above show that the ways a firm learns have a major impact on their ability to develop dynamic capabilities (Teece, 2007). This perspective includes elements such as cognition, rationality, and governance (Noteboom, 2009). The study of learning within this framework goes well beyond the variations in initial learning attempts (Bingham and Davis, 2012) and includes the development of the ability to learn over time and space as well as from failure (Zollo and Winter, 2002). Only a few studies have connected capability development to these elements. Neither have the microfoundations of learning comprehensively been identified and theoretically integrated (Crossan, Maurer, and White, 2011; Felin and Foss, 2009). Existing work on knowledge transfer across groups (e.g., Darr, Argote, and Epple, 1995), combined with recent advances in empirically modeling knowledge transfer across individual employees (Chan, Li, and Pierce, 2014), provide promise for decomposing the persistence and adaptation of routines under dynamic workforces and competitive environments.

King and Tucci (2002) demonstrate the promise of using panel data to study the sources of dynamic capabilities in experience with sales and production, and with the transformational activities of new market entry. In their work on the disk-drive industry, they use panel data to identify the effect of both experience in existing markets and experience with new market niche entry on new entry and performance. They find evidence that while many 
incumbent firms miss market opportunities, static experience from past production and sales actually led to entry and increased sales. Furthermore, they find no evidence that transformational experience, or experience from previous market entry, increases entry or success of entry. Their results suggest that dynamic capabilities may come from multiple types of experience, and that the routines developed in existing markets may yield success in new endeavors as much as they may yield unhealthy inertia.

King and Tucci acknowledge, however, that their results suggesting that market entry experience does not encourage future entry may be the result of limited resources for market entry. Their results indicate that further studies using panel data are important in linking transformational experience with dynamic capabilities. It may be fruitful for researchers to explore how experience in integrating and divesting diverse (or related) assets may lead to superior performance in diversified corporations (Moliterno and Wiersema, 2007; Barreto, 2010). Can the number of past acquisitions and divestments predict higher returns in new markets or acquisitions? Acknowledging the importance of industry and firm-level controls, this empirical approach may yield a better understanding of whether dynamic capabilities stem from past transformational or dynamic activities.

Another idea, briefly pursued by Rindova and Taylor (2002), involves measuring the heterogeneous effects of exogenous shocks on firm profitability and survival. Their project examines how firms in defense-related IT and biotechnology reacted to the terrorist attacks of September 11, 2001, and while the use of exogenous shocks to identify performance is hardly new, this approach is promising for dynamic capabilities. While Rindova and 
Taylor's approach also involves small sample studies, the promise for a broader empirical study is evident. The terrorist attacks provide a severe, exogenous shock with effects in numerous industries. This shock may allow empirical researchers to better identify those firm characteristics that predict successful adaptation across multiple industries, each effected uniquely by the natural experiment.

Another area of promise for empirical work in dynamic capabilities involves work on entrepreneurial spinoffs. Recent work has explored why some innovations remain within corporations while others are developed through outside entrepreneurial ventures (Burton et al., 2001; Klepper and Sleeper, 2002). As Klepper (2001) has argued, spinoffs may result from the competence-destroying innovations first explicated by Tushman and Anderson (1986), often resulting in lost profits for the source firm. The key for incumbent firms may be in acquiring the complementary assets necessary for commercializing radical innovations (Teece, 1986; Zingales, 2000). The dynamic capability of a firm may be measured in the success of intrapreneurship vs. entrepreneurial spinoffs. Furthermore, this work on spinoffs holds promise in identifying how capabilities may reside in management or management practices (Feldman, 2016). If the source firms are important to the success of spinoffs as Burton et al. (2001) suggest, this success may stem from managerial routines learned in the source organization (Klepper and Sleeper, 2002).

It is our hope that current work on dynamic capabilities will inform future research to the same degree that Cyert and March and Nelson and Winter have informed us (Helfat and 
Winter, 2011), moving us closer to a deeper understanding of the sources of firm-level competitive advantage.

\section{Conclusion}

Dynamic capabilities theories of the business enterprise are gaining traction in organization theory and in strategic management. We traced the crucial contributions of Cyert and March and Nelson and Winter to the development of dynamic capabilities theories and how they can inform current debates and future directions in this literature. We detail the lineage of Eisenhardt and Martin's dynamic capabilities and tie them to a behavioral tradition with its implications for management research. Similarly, we point out how Teece and colleagues built a dynamic capability framework on the work of evolutionary theorists with much potential to explore the role of managers and employees within this framework, the microfoundations of dynamic capabilities, and its implications for management practice.

The schism between the Eisenhardt and Teece view is not banal or trivial. It has hindered theoretical development that has been burked by semantic similarities. Research using dynamic capabilities needs to be much more careful and explicit about the theoretical assumptions it applies. It is crucial for researchers to make a clear distinction between the two approaches if the field wants to continue to create knowledge.

Dynamic capabilities have evolved and expanded considerably to incorporate notions from strategic management (e.g. business models), innovation studies (e.g. capturing value / appropriability) behavioral decision theory (e.g. sensing and seizing blunders and biases) 
and organization behavior (e.g. culture/leadership issues). It is this rich panoply which the framework embraces that makes it distinctive and a powerful framework to help shape understanding of both management and policy issues. More work clearly needs to be done and is being done; but our belief is that the dynamic capabilities research stream is honing a theory of the firm that will connect meaningfully with the fundamental management and policy issues of our time.

\section{References}

Adner, R. and Helfat, C.E. (2003), 'Corporate effects and dynamic managerial capabilities', Strategic Management Journal, 24, 1011-1025.

Arend, R. and Bromiley, P. (2009), 'Assessing the dynamic capabilities view: spare change, everyone?', Strategic Organization, 7, 75-90.

Arndt, F. and Bach, N. (2015), 'Evolutionary and ecological conceptualization of dynamic capabilities: Identifying elements of the Teece and Eisenhardt school', Journal of Management and Organization, 21(5), in press.

Augier, M. and Teece, D.J. (2009), 'Dynamic capabilities and the role of managers in business strategy and economic performance', Organization Science, 20, 410-421.

Barreto, I. (2010), 'Dynamic capabilities: a review of past research and an agenda for the future', Journal of Management, 36, 256-280.

Robert Baum, J. and Wally, S. (2003), 'Strategic decision speed and firm performance', Strategic Management Journal, 24(11), 1107-1129.

Becker, M. C., Knudsen, T. and March, J. G. (2006), 'Schumpeter, Winter, and the sources of novelty', Industrial and Corporate Change, 15(2), 353-371.

Bingham, C.B. and Davis, J.P. (2012), 'Learning sequences: their existence, effect, and evolution', Academy of Management Journal, 55, 611-641.

Brown, S. L. and Eisenhardt, K. M. (1997), 'The art of continuous change: Linking complexity theory and time-paced evolution in relentlessly shifting organizations', Administrative Science Quarterly, 1-34.

Brown, S. L. and Eisenhardt, K. M. (1998). Competing on the edge: Strategy as structured chaos. Harvard Business Press.

Burton, M., Sorensen, J., and Beckman, C. (2002), 'Coming from good stock: career histories and new venture formation', Research in the Sociology of Organizations, 19, 229-262.

Chan, T., Li, J., and Pierce, L. (2014), 'Learning from peers: knowledge transfer and sales force productivity growth', Marketing Science, 33, 463-484. 
Chesbrough, H. and Rosenbloom, R.S. (2002), 'The role of the business model in capturing value from innovation: evidence from Xerox corporation's technology', Industrial and Corporate Change, 11, 529-555.

Cohen, M. D. (2006), 'What's different is routine,' Industrial and Corporate Change, 15(2), 387-390.

Cyert, R.M. and March, J.G. (1963), A behavioral theory of the firm. Englewood Cliffs, NJ: Prentice-Hall.

Crossan, M.M., Maurer, C.C., and White, R.E. (2011), 'Reflections on the 2009 AMR decade award: do we have a theory of organizational learning?', Academy of Management Review, 36, 446-460.

Darr, E., Argote, L., and Epple, D. (1995), 'The acquisition, transfer and depreciation of knowledge in service organizations: productivity in franchises', Management Science, 41, 1750-1762.

Di Stefano, G., Peteraf, M. and Verona, G. (2010), 'Dynamic capabilities deconstructed z: a bibliographic investigation into the origins, development, and future directions of the research domain', Industrial and Corporate Change, 19(4), 1187-1204.

Di Stefano, G., Peteraf, M. and Verona, G. (2014), 'The organizational drivetrain: A road to integration of dynamic capabilities research, The Academy of Management Perspectives, 28(4), 307-327.

Durand, R. (2003), 'Predicting a firm's forecasting ability: The roles of organizational illusion of control and organizational attention', Strategic Management Journal, 24(9), 821-838.

Eisenhardt, K. M. (1998), Strategic decision making as improvisation (pp. 251-257). Springer US.

Eisenhardt, K. M. and Martin, J. A. (2000), 'Dynamic capabilities: what are they?', Strategic Management Journal, 21(10-11), 1105-1121.

Evans, D.S. (2003), 'The antitrust economics of multi-sided platform markets', Yale Journal on Regulation, 20.

Feldman, E. (2016), 'Corporate spinoffs and corporate allocation decisions', Strategy Science, forthcoming.

Felin, T. and Foss, N.J. (2009), 'Organizational routines and capabilities: historical drift and a course-correction toward microfoundations', Scandinavian Journal of Management, 25, 157-167.

Gary, M.S. and Wood, R.E. (2011), 'Mental models, decision rules, and performance heterogeneity', Strategic Management Journal, 32, 569-594.

Gavetti, G. (2005), 'Cognition and hierarchy: rethinking the microfoundations of capabilities' development', Organization Science, 16, 599-617.

Helfat, C.E., and Winter, S.G. (2011), 'Untangling dynamic and operational capabilities: strategy for the (N) ever-changing world', Strategic Management Journal, 32, 1243-1250.

Helfat, C. E., \& Peteraf, M. A. (2015), 'Managerial cognitive capabilities and the microfoundations of dynamic capabilities', Strategic Management Journal, 36(6), 831850. 
Hodgkinson, G. P. and Healey, M. P. (2011). Psychological foundations of dynamic capabilities: reflexion and reflection in strategic management. Strategic Management Journal, 32(13), 1500-1516.

Kaplan, S. (2011), 'Research in cognition and strategy: reflections on two decades of progress and a look to the future', Journal of Management Studies, 48, 665-695.

Klarner, P. and Raisch, S. (2013), 'Move to the beat-Rhythms of change and firm performance', Academy of Management Journal, 56, 160-184.

King, A. and Tucci, C. (2002), 'Incumbent entry into new market niches: the role of experience and managerial choice in the creation of dynamic capabilities', Management Science, 48, 171-186.

Klepper, S. (2001), Employee startups in high-tech industries, Industrial and Corporate Change, 10, 639-674.

Klepper, S. and Sleeper, S. (2002), Entry by spinoffs. Unpublished Manuscript, Carnegie Mellon University.

Laamanen, T. and Wallin, J. (2009), 'Cognitive dynamics of capability development paths', Journal of Management Studies, 46, 950-981.

Laureiro-Martínez, D., Brusoni, S., Canessa, N. and Zollo, M. (2015), 'Understanding the exploration-exploitation dilemma: An fMRI study of attention control and decisionmaking performance', Strategic Management Journal, 36: 319-338.

Lavie, D, (2006), 'Capability reconfiguration: an analysis of incumbent responses to technological change', Academy of Management Review, 31, 153-174.

Levinthal, D. (2006), 'The Neo-Schumpeterian theory of the firm and the strategy field', Industrial and corporate change, 15(2), 391-394.

March, J.G. and Simon, H.A. (1958), Organizations. New York: Wiley.

March, J. G. (1991), 'Exploration and exploitation in organizational learning', Organization science, 2(1), 71-87.

Markides, C. (2006), 'Disruptive innovation: in need of better theory', Journal of Product Innovation Management, 23, 19-25.

Moliterno, T.P. and Wiersema, M.F. (2007), 'Firm performance, rent appropriation, and the strategic resource divestment capability', Strategic Management Journal, 28, 1065-1087.

Nelson, R.R. and Winter, S.G. (1982), An evolutionary theory of economic change. Cambridge: Belknap Press.

Nooteboom, B. (2009), A cognitive theory of the firm: learning, governance and dynamic capabilities. Edward Elgar Publishing.

Ocasio, W. (1997), 'Towards an attention-based view of the firm', Strategic Management Journal, 18, 187-206.

Peteraf, M., Di Stefano, G., and Verona, G. (2013), 'The elephant in the room of dynamic capabilities: Bringing two diverging conversations together'. Strategic Management Journal, 34, 1389-1410.

Rindova, V., and Taylor, S. (2002), 'Dynamic capabilities as macro and micro organizational evolution', Robert H. Smith School of Business-Smith Papers Online: 1, 11. 
Schreyögg, G. and Kliesch-Eberl, M. (2007), 'How dynamic can organizational capabilities be? Towards a dual-process model of capability dynamization', Strategic Management Journal, 28, 913-933.

Schreyögg, G. and Sydow, J. (2010), 'Crossroads — organizing for fluidity? Dilemmas of new organizational forms', Organization Science, 21, 1251-1262.

Schumpeter, J.A. (1934), The theory of economic development. Cambridge, MA: Harvard University Press.

Simon, H. (1955), 'A behavioral model of rational choice', Quarterly Journal of Economics, 69, 99-118.

Simon, H. (1957), Administrative behavior: a study of decision-making processes in administrative organization. New York: Wiley.

Staber, U. and Sydow, J. (2002), 'Organizational adaptive capacity: a structuration perspective', Journal of Management Inquiry, 11, 408-424.

Teece, D. J. (1986), 'Profiting from technological innovation: Implications for integration, collaboration, licensing and public policy', Research policy, 15(6), 285-305.

Teece, D.J. (2007), 'Explicating dynamic capabilities: the nature and microfoundations of (sustainable) enterprise performance', Strategic Management Journal, 28, 1319-1350.

Teece, D.J. (2010), 'Business models, business strategy and innovation', Long Range Planning, 43, 172-194.

Teece, D.J. (2014a), 'A dynamic capabilities-based entrepreneurial theory of the multinational enterprise', Journal of International Business Studies, 45, 8-37.

Teece, D.J. (2014b), 'The foundations of enterprise performance: dynamic and ordinary (managerial and organizational) capabilities in an (economic) theory of firms', Academy of Management Perspectives, 28, 328-352.

Teece, D.J., Pisano, G., and Shuen, A. (1997), 'Dynamic capabilities and strategic management', Strategic Management Journal, 18, 509-533.

Tushman, M. and Anderson, P. (1986), 'Technological discontinuities and organizational environments', Administrative Science Quarterly, 31, 439-465.

Vandaie, R. and Zaheer, A. (2014), 'Surviving bear hugs: Firm capability, large partner alliances, and growth', Strategic Management Journal, 35: 566-577.

Winter, S.G. (2003), 'Understanding dynamic capabilities', Strategic Management Journal, 24, 991-995.

Winter, S. G. (2006), 'Toward a neo-Schumpeterian theory of the firm', Industrial and Corporate Change, 15(1), 125-141.

Zingales, L. (2000), 'In search of new foundations', The Journal of Finance, 55, 1623-1653.

Zollo, M. and Winter, S.G. (2002), 'Deliberate learning and the evolution of dynamic capabilities', Organization Science, 13, 339-351.

Zott, C. (2003), 'Dynamic capabilities and the emergence of intraindustry differential firm performance: insights from a simulation study', Strategic Management Journal, 24, 97125. 
